Motrivivência $\quad$ v. 26 , n. 43 , p. $164-182$, dezembro/2014

\title{
ANCORAGEM DA REPRESENTAÇÃO SOCIAL DA EDUCAÇÃO FÍSICA ESCOLAR NAS ABORDAGENS TEÓRICAS DA EDUCAÇÃO FÍSICA
}

Fátima Ferreira Vasconcelos Pedro Humberto Faria Compos²

\section{RESUMO}

Este estudo se propôs investigar a prática da Educação Física nas escolas sob a ótica da Teoria das Representações Sociais na busca da identificação da ancoragem das representações sociais nos Modelos Teóricos desta disciplina. Baseado em estudo anterior onde a representação social identificada está fundamentada nos elementos: LÚDICO e DESENVOLVIMENTO como elementos centrais, os resultados obtidos no atual estudo indicam que a Representação Social identificada está ancorada nas abordagens: Desenvolvimentista e Psicomotora. Podemos sugerir ainda que a prática da Educação Física Escolar está a serviço do DESENVOLVIMENTO e este desenvolvimento é promovido principalmente por meio de estratégias LÚDICAS e ESPORTIVAS.

Palavras-chave: Representações Sociais; Educação Física Escolar

1 Mestre em Educação. Docente da SEERJ, Colégio Cruzeiro e Universidade Souza Marques. Rio de Janeiro, Brasil. E-mail: mffv@ig.com.br

2 Doutor em Psicologia Social. Docente da UNESA/UERJ - Rio de Janeiro, Brasil.

E-mail: pedrohumbertosbp@terra.com.br 


\section{Educação física escolar e sua trajetória no Brasil}

A Educação Física é uma área de conhecimento que se propõe estudar e atuar sobre um conjunto de práticas ligadas ao corpo e ao movimento (DAOLIO, 1996). De acordo com a literatura da área ainda não há um consenso no que se refere à definição da Educação Física enquanto campo científico e a Educação Física como prática educativa exercida no ambiente escolar (DARIDO e RANGEL, 2008; RETONDAR, 2009; REZER, 2009; BRACHT; GONZÁLES, 2005) Assim como a legislação que determina a prática da Educação Física nas instituições educacionais brasileiras que também nem sempre se apresentou com os conteúdos hoje vigentes.

Os primeiros registros da Educação Física em instituições de "instrução" datam do Período Imperial como uma atividade cujo objetivo era educar o corpo (ACCIOLY; MARINHO, 1956). Sua prática foi marcada por um exercício em instituições escolares orientadas por interesses políticos e culturais ao longo de um vasto período onde modelos teóricos específicos ditaram sua prática: higienismo, militarismo, tecnicismo e esportivismo (DARIDO e RANGEL, 2008). Desde 1996 a Educação Física Escolar tem como determinação legal, a Lei de Diretrizes e Bases n 9.394/96, na qual é expresso que esta é componente curricular obrigatório da educação básica responsável pela promoção do desenvolvimento do educando nos aspectos físico, moral, psíquico e social.

A trajetória da regulamentação da Educação Física nas escolas é marcada por leis que induzem a uma compreensão desta como um instrumento cuja principal função inicialmente era o desenvolvimento de aptidões físicas e prática de esportes (BRASIL, 1971). E atualmente podemos perceber acrescidos a estes objetivos, determinações voltadas ao desenvolvimento moral, social, psíquico e cívico (BRASIL, 1971).

A legislação atual estabelece não só a Educação Física como disciplina curricular obrigatória em igualdade de proposições às demais, mas também orientam uma prática abrangente que se expande para além das propostas vinculadas às atividades corporais. Isto fortalece o papel de elementos conceituais como o conhecimento do corpo e práticas para a qualidade de vida, no seu ensino (BRASIL, 2000).

Este conceito foi decorrente do crescimento que aconteceu no campo de conhecimento da Educação Física por volta dos anos 80, quando autores de referência (HILDEBRANDT, 1986; LE BOULCH, 1986; TANI, 1988; MEDINA, 1983; SERGIO, 1987; CASTELLANI FILHO, 1988; FREIRE, 1989) realizaram produções teóricas significativas que trouxeram um olhar crítico sobre a ação desta disciplina nas escolas. Este crescimento teórico-metodológico promoveu o surgimento de novas abordagens (LAVOURA, T. N.; BONTURA, H. M. L.; DARIDO, S. C. 2006).

No entanto, apesar de identificarmos nas redações das leis relativas à Educação Física nas escolas, determinações para a de uma elaboração curricular visando a formação do aluno em sua totalidade, a literatura da área sugere que a Educação Física Escolar constitui uma prática que não condiz com estas orientações ou ainda que pouco contribui para alcançar tais objetivos (DARIDO e RANGEL, 2008; RETONDAR, 2009; REZER, 2009; BRACHT; GONZÁLES, 2005). 
Neste contexto, podemos ressaltar que apesar do movimento de renovação teórico-metodológica que ocorreu nos anos 80 , promovendo uma ruptura com as concepções existentes até então ${ }^{3}$ e causando o desenvolvimento de novas concepções ${ }^{4}$ a realidade nas escolas ainda encontra-se marcada pela existência de uma Educação Física que não está sob a regência dessas novas concepções (SILVA, 2007; RETONDAR, 2009; REZER, 2009).

Para Fensterseifer (2009), o "abismo" presente entre o que é proposto em seu campo de conhecimento, legislação que rege seu exercício e a realidade pedagógica existente nas instituições de ensino não é o único problema da Educação Física Escolar. Estudos no campo da Teoria das Representações Sociais mostram que a esta é vista como uma disciplina de menor valor pedagógico em comparação com as demais por diretores, alunos e outros professores (CARVALHO, 2006; BRACHT; GONZÁLES, 2005).

Estudos que tratam das representações sociais da Educação Física Escolar (PEREIRA, 2007; CARVALHO, 2006; SÁ, 2006; BRACHT; GONZÁLES, 2005, RETONDAR, 2009; SILVA, 2007) apontam que professores das demais disciplinas, coordenadores, diretores de escola e alunos possuem representações desta como um componente curricular de menor valor pedagógico, de "status" inferior às demais, como uma disciplina de menor valor para a formação do aluno e de descompromisso com o conhecimento acadêmico.Apontam ainda que as representações identificadas desta disciplina não estão amparadas em conceitos claros de seu campo de conhecimento. Ou seja, a própria visão desta, enquanto disciplina escolar está marcada por um conflito entre diversas abordagens instaladas desde o início de sua prática em instituições de ensino. O que sugere uma inconsistência entre a prática da Educação Física como disciplina escolar e as representações sociais desta elaborada pelos seus professores.

Segundo ainda estes estudos (PEREIRA, 2007; CARVALHO, 2006; SÁ, 2006; BRACHT; GONZÁLEZ, 2005, RETONDAR, 2009; SILVA, 2007), uma transformação desta prática pode ser vislumbrada e vir a se configurar na realidade a partir da compreensão mais profunda do modo como a Educação Física Escolar é exercida hoje nas escolas. Compreender a Educação Física Escolar como prática pressupõe uma compreensão da percepção que os professores desta disciplina têm da função pedagógica da Educação Física e seus conteúdos específicos como: concepção de corpo, movimento, esporte e atividade física. A compreensão de como os professores tem incorporados estes conceitos pode ser extraída da identificação das representações sociais que estes sujeitos possuem da Educação Física Escolar e também do conhecimento da modalidade de construção destas representações, ou seja, do conhecimento dos modelos teóricos da Educação Física que sustentam estas representações.

3 Higienista, militarista e esportivista.

4 Desenvolvimentista, construtivista cultura, crítico-Superadora, crítico-emancipatória, saúde-renovada, PCNs e psicomotora. 


\section{Modelos teóricos da educação física}

A Educação Física nas escolas é marcada por concepções advindas e orientadas por interesses sócio-políticos desde o início de sua existência, organizados ao longo de um vasto percurso histórico em função de mudanças no contexto social e político que continuamente ditou regras e enfoques a serem adotados por esta disciplina.

Os modelos teóricos, também denominados de concepções ou abordagens metodológicas sofreram contínuas modificações ao longo dos anos em decorrência do surgimento de diversas tendências pedagógicas no sistema educacional brasileiro. Estes modelos teóricos, na medida em que foram surgindo e sofrendo modificações, seguiram impregnando valores e comportamentos à realidade da Educação Física desde o seu início. Este fato promoveu uma rede de "sentidos e significados vinculados às propostas corporais tematizadas e construídas por essa prática social no âmbito da instituição escolar" (BRACHT, 2010, P. 94).

O início da existência da Educação Física nas escolas foi marcado pela dominância de uma concepção que era baseada na perspectiva higienista, onde a temática principal era a preocupação com hábitos de higiene e saúde que deveriam ser obtidos através de exercícios físicos, havia uma valorização do desenvolvimento físico e moral. (DARIDO; RANGEL, 2008, CASTELLANI FILHO, et al, 2009).

Os objetivos da Educação Física escolar passaram a seguir, a ser organizados de acordo com um novo modelo: o modelo militarista, onde a principal preocupação é a formação de indivíduos com prontidão para enfrentar situações de guerra, capazes de suportar o combate, a luta e a guerra.
Neste período sua ação nas escolas mantinha estreita semelhança com a "instrução física militar"(DARIDO; RANGEL, 2008, CATELLANI FILHO, et al, 2009).

Após o período das grandes guerras, a Educação Física Escolar, passou a receber influência da Escola-Nova, sob a orientação do educador Dewey. passando então a ser compreendida como um veículo de educação. A postura do professor e sua ação nas escolas gradativamente vão sofrendo alterações a partir da mudança do discurso influenciado pelo movimento escolanovista que atinge o auge no início dos anos 60, no entanto logo vem a ser interrompido com o advento da ditadura militar no Brasil (DARIDO; RANGEL, 2008, CATELLANI FILHO, et al, 2009).

A partir deste momento a Educação Física nas escolas passou a ter como principal objetivo o ensino dos esportes, sob a orientação do modelo esportivista, também chamado de mecanicista, tradicional ou tecnicista. Neste contexto é iniciado um movimento de intenso investimento dos governos militares no esporte, fazendo desta disciplina a estrutura ideológica para a prática esportiva. A intenção deste movimento era a promoção do País por meio dos sucessos obtidos em competições de alto nível, transmitindo com isso a ideia de "Brasil-potência", "prosperidade e desenvolvimento" e eliminando as críticas internas (DARIDO; RANGEL, 2008, BETTI, 2005, BRACHT, 1999).

Em função destas características, iniciaram-se críticas severas ao modelo esportivista a partir dos anos 80 o que provocou o surgimento de um novo modelo teórico cujo objetivo era orientar uma realidade onde o professor parte de um papel extremamente diretivo e centralizador 
para um papel de intervenção mínima. Este novo modelo foi denominado de recreacionista. Há a ideia de que este modelo é supostamente decorrente de "interpretações inadequadas e condições de formação e trabalho do professor" (DARIDO; RANGEL, 2008, p. 27).

Após o acontecimento da "Abertura" política no Brasil, a Educação Física Escolar recebeu influência de novos movimentos decorrentes de avanços nas pesquisas educacionais e um aprofundamento científicoe da oposição oferecida aos modelos até então vigentes. A partir de então, a Educação Física nas escolas conta com a contribuição de várias concepções: Psicomotricista, desenvolvimentista, saúde-renovada, interacionista - construtivista, além de outras. Estas abordagens trouxeram para a Educação Física nas escolas uma proposta de Educação formadora com propósitos pedagógicos.

Darido e Rangel (2008) relatam que, ao final da década de 70 as aulas de Educação Física receberam orientações da Educação Psicocinética desenvolvida pelo professor Jean Le Bouch. Esta orientação passou a constituir uma nova tendência pedagógica da Educação Física que foi denominada de Psicomotricista. Esta abordagem foi o primeiro movimento mais estruturado que surgiu em oposição aos modelos anteriormente vigentes. De acordo com Le Boulch (1986), o enfoque principal deste modelo é o desenvolvimento da criança em seus aspectos cognitivo, afetivo e psicomotor, com fins de qualificar o processo de aprendizagem sob a concepção de formação integral do aluno. (LE BOULCH, 1986).

$\mathrm{Na}$ abordagem desenvolvimentista o movimento constitui-se o principal meio e fim da Educação Física, o que garante a especificidade de seu objeto. As aulas são organizadas com o propósito de privilegiar a aprendizagem do movimento com respeito à faixa etária do aluno,a aquisição de habilidades motoras e baseada em princípios do Desenvolvimento Motor e da Aprendizagem Motora (BARBIERI; PORELLI; MELLO, 2010).

\section{A abordagem saúde - renovada} propõe uma metodologia baseada na aptidão física relacionada à saúde e estabelece como objetivos: informação, mudança de atitudes e promoção da prática sistemática de exercícios. Esta abordagem incorporou certos princípios da orientação oferecida nos PCNs fazendo com que expressasse um diferencial em suas propostas em relação ao modelo biologicista e higienista vigentes na década de 60 (CAMPOS, 2011).

Em oposição à proposta mecanicista também foi formulado o método construtivista-interacionista que tem presença significativa no contexto escolar. Esta proposta busca apoio nas teorias desenvolvidas por Vigotisky e Piaget, deste modo se constitui uma proposta que mantém estreita ligação com a proposta pedagógica escolar mais ampla, não estabelecendo prioridade para objetivos relacionados ao corpo e ao movimento. (DARIDO; RANGEL, 2008).

De acordo com Rezer (2009), as Ciências humanas e Sociais foram fundamentalmente incorporadas na produção de conhecimento que ocorreu por volta dos anos 80 e 90. Este movimento permitiu um questionamento profundo em relação aos pressupostos que legitimavam a Educação Física. Foram então formuladas outras propostas e organizadas como abordagens metodológicas.

A abordagem crítico-superadora foi desenvolvida por um "coletivo de autores" Valter Bracht, Lino Castellani Filho, Carmem 
Soares, Celi Taffarel formulada com bases no marxismo e neo-marxismo, tendo também recebido influência dos educadores José Carlos Libâneo e Demerval Saviani. O que trás para esta abordagem concepções de poder, interesse, esforço e contestação, valorização do resgate histórico e da contextualização dos fatos. (BARBIERI; PORELLI; MELLO, 2010).

\section{A abordagem crítico - emancipa-}

tória foi desenvolvida por ElenorKunz em 1994, baseada na pedagogia de Paulo Freire e tem como proposta a compreensão crítica do mundo, da sociedade e de suas relações sem, no entanto objetivar a transformação social a partir da intervenção escolar. Esta abordagem é considerada um desdobramento da tendência crítica. (CAMPOS, 2011).

O modelo orientado pelos $\underline{\text { PCN }}$ tem como proposta uma adequação dos currículos sugeridos para a Educação Física nas escolas promovendo uma orientação curricularno Brasil. Este modelo toma como referencial a LDB, Lei n 9394/96 (BRASIL, 1996) que orienta a prática da Educação Física Escolar integrada à proposta pedagógica da escola em adequação a faixa etária e condições do conjunto social, assim como o exercício pleno da cidadania (CAMPOS, 2011). A proposta oferecida no modelo orientado pelo PCN é a construção crítica da cidadania deve ser elaborada a partir de temas transversais como: ética, saúde, meio ambiente, pluralidade cultural, orientação sexual, trabalho e consumo. Estes conteúdos sustentam semelhança conceitual aos conteúdos indicados pelas abordagens críticas (CAMPOS, 2011).

De acordo com Darido (2003) e Bracht (1999), a Educação Física apresenta uma realidade que sempre atendeu a concepções diferenciadas e peculiares a cada momento histórico, regida por distintas ideologias inerentes ao período vivido por nossa sociedade.Hoje, nas aulas de Educação Física, "as perspectivas pedagógicas que se instalam não aparecem de forma "pura", mas com características particulares, mesclando aspectos de mais de uma linha pedagógica (CATELLANI FILHO, et al, 2009, WATANABE; BIM, 2012). Dizendo de um outro modo, Darido e Rangel (2008) relatam que os professores de Educação física afirmam que dificilmente seguem uma única abordagem, aplicando o que cada uma pode oferecer de mais coerente com a especificidade de cada realidade.

Esta característica identificada a respeito da Educação Física Escolar nos impulsiona a buscar elementos que indiquem caminhos para a solução destas questões e esta pesquisa se propõe a fazer uma leitura da realidade descrita por meio dos instrumentos oferecidos pela Teoria das Representações Sociais.

\section{Estudos de Representações Sociais da edu- cação física escolar}

Em revisão bibliográfica realizada em dissertações, teses e artigos que tratam da visão que existe constituída da Educação Física Escolar e também estudos que tratam das representações sociais da Educação Física Escolar (PEREIRA, 2007; CARVALHO, 2006; SÁ, 2006; BRACHT; GONZÁLEZ, 2005, RETONDAR, 2009; SILVA, 2007) foi possível constatar que professores das demais disciplinas, coordenadores, diretores de escola e alunos possuem representações desta como um componente curricular de menor valor pedagógico, de "status" inferior às demais. Estes estudos identificaram que 
as representações sociais construídas sobre a Educação Física na escola a concebem-na como uma disciplina de menor valor para a formação do aluno e de descompromisso com o conhecimento acadêmico.

Os dados obtidos nestes estudos nos permitem a identificação do panorama das representações sociais sobre a realidade da Educação Física nas escolas. Os estudos apresentados acima sugerem que a Representação Social da Educação Física Escolar indicam uma prática de menor valor pedagógico, de "status" inferior às demais, como uma disciplina de menor valor para a formação do aluno e de descompromisso com o conhecimento acadêmico. Ainda apontam uma fragilidade teórica de sustentação a esta prática, indicando uma ancoragem estruturada em diversos modelos teóricos onde se percebe uma inconsistência teórica de suporte a esta prática. Os estudos de Carvalho (2006) e Sá (2006) indicam sugestões de ações pedagógicas aos professores desta disciplina para que as representações sociais possam ser construídas a partir de "novos acordos" conceituais. Retondar (2009) e Silva (2007) fornecem informações e reflexões a respeito das necessidades inerentes à formação e os pressupostos essenciais para a constituição efetiva da realização qualitativa desta disciplina.

Apenas a identificação das representações sociais que os professores elaboram desta disciplina, que se mostra "conflituosa",não é suficiente para compreender essa prática. Parece-nos pertinente, portanto para além da identificação da estrutura das representações sociais que os próprios professores de Educação Física elaboram sobre a sua prática, a identificação a ancoragem destas representações.
Os estudos apresentados apontam que as representações sociais da Educação Física Escolar, elaboradas pelos próprios professores da área, não estão amparadas em conceitos claros de seu campo de conhecimento. Ou seja, a própria visão desta, enquanto disciplina escolar está marcada por um conflito entre diversas abordagens instaladas desde o início de sua prática em instituições de ensino. Há, portanto uma inconsistência entre a prática da Educação Física como disciplina escolar e as representações sociais desta elaborada pelos seus professores.

Este estudo, portanto se propôs a investigar a respeito das representações sociais da prática da Educação Física Escolar por seus professores orientando a investigação na busca de identificação da ancoragem das representações sociais já identificadas desta prática em estudo anterior. E, para que este objetivo fosse alcançado, buscamos uma aproximação com os elementos que originam a composição desta prática. A Teoria das Representações Sociais, sob a proposta da abordagem estrutural, nos ofereceu os instrumentos de coleta e análise dos dados necessários e adequados para tal intuito. Para que possamos entender porque essa Teoria oferece tal possibilidade, vamos sucintamente apresentar o campo conceitual que sustenta esta Teoria com o intuito de justificar criteriosamente a nossa escolha.

\section{Teoria das Representações Sociais}

A Teoria das Representações Sociais, proposta por Serge Moscovici em 1961, situa-se no domínio de conhecimento da Psicologia Social e tem como proposta 
o estudo das relações intergrupais. É uma teoria que se propõe estudar as relações entre os indivíduos e os grupos, nas quais os indivíduos constroem explicações sobre objetos sociais por meio das interações sociais estabelecidas (MOSCOVICI, 2010), além de nos permitir conhecer uma representação como um saber socialmente constituído e partilhado com fins de construção de uma realidade comum aos indivíduos de um determinado grupo social (DESCHAMPS; MOLINER, 2009). Segundo Abric (2000, p. 27), "A identificação da "visão de mundo" que os indivíduos ou os grupos têm e utilizam para agir e para tomar posição, é indispensável para compreende à dinâmica das interações sociais e clarificar os determinantes das práticas sociais".

Jean-Claude Abric em 1976 desenvolveu a conceituação de representação social associando a ideia de estrutura à definição dada inicialmente por Moscovici, fundando a Teoria do Núcleo Central. Sob esta ótica a representação social deve ser entendida como um sistema estruturado composto por um conjunto de opiniões, informações, atitudes e crenças organizadas em torno de uma significação central a propósito de um dado objeto (ABRIC, 2001).

A identificação das representações sociais dos professores de Educação Física sob a orientação da abordagem estrutural propicia, portanto, a compreensão destas representações em sua estrutura, organização e hierarquização. Segundo Abric (2000) a abordagem estrutural nos permite analisar qualitativamente questões relativas às ciências sociais como a compreensão e o desenvolvimento do pensamento social, a prática dos grupos no que se refere às suas atitudes e opiniões, a influência destes elementos no ambiente social assim como a organização interna dos grupos e suas regras de transformação social. Portanto, segundo este autor, não apenas é confirmada a importância do estudo das Representações Sociais para a compreensão das práticas sociais, como também é necessária para a análise dos processos de influência social e de transformação das representações dos diversos grupos.

Ainda segundo este autor Abric (2001), a Teoria do Núcleo Central entende que as representações sociais, em seu funcionamento, possuem uma dupla lógica, organizada segundo seus componentes cognitivo e social, portanto é concebida como um sistema sócio cognitivo. Segundoesta Teoria as representações estão organizadas em torno de um núcleo central acompanhado por outros elementos periféricos que dão significado a esta representação.

O estudo das Representações Sociais orienta também a análise das práticas, na busca da identificação da ancoragem destas representações, na busca da compreensão dos elementos onde estas estão amparadas, como foram construídas. O estudo da ancoragem das representações sociais nos permite identificar os princípios organizadores aos pontos de referência que orientam as condições e os termos de discussão e elaboração do pensamento sobre um dado objeto social, que são compartilhados (WALCHELKE; CAMARGO, 2007).

Estudar a prática educativa através da Teoria das Representações Sociais tem sua validade na medida em que as práticas são entendidas nesta teoria como um conjunto de elementos de natureza cognitiva e comportamental, as práticas são concebidas 
como conjuntos organizados e historicamente construídos de condutas (CAMPOS, 2003). Neste sentido, conhecer a estrutura da Representação social de um determinado objeto é um processo que nos permite conhecer o que os sujeitos envolvidos pensam sobre a sua prática.

\section{Estudo da estrutura da Representação Social da educação física escolar e sua ancoragem nas abordagens teóricas}

O presente estudo buscou estudar a ancoragem das práticas nos modelos teóricos. Assim, alguns elementos do campo representacional foram estudados, articuladoscom o foco no estudo da ancoragem do conteúdo das representações sociais e das práticas nas abordagens teóricas, com a perspectiva de discutir a influência dos modelos teóricos na prática, através da adesão dos professores de Educação Física aos princípios operacionais de cada abordagem.

Apoiamos a pesquisa realizada em estudos preliminares sob a orientação da Teoria das Representações Sociais de acordo com os pressupostos teóricos da abordagem estrutural, onde foram identificados o conteúdo e a organização das representações sociais da Educação física Escolar por professores desta disciplina. Neste estudo preliminar, a hipótese gerada a respeito da Representação Social da Educação física Escolar por seus professores é que esta é constituída de elementos como o DESENVOLVIMENTO e o LÚDICO como elementos supostamente centrais e ESPORTE, CORPO e MOVIMENTO como elementos periféricos desta representação.

\section{MÉTODO}

No estudo atual foi aplica do um questionário composto por questões com o objetivo de identificar a ancoragem das representações que estes professores elaboram sobre a Educação Física Escolar nas diferentes abordagens metodológicas da Educação Física. O questionário foi composto por doze escalas com o objetivo de indagar a respeito das concepções teórico-metodológicas vinculadas às estratégias prováveis de utilização nas aulas de Educação Física. As questões foram distribuídas em equilíbrio numérico entre as abordagens escolhidas, foram confeccionadas quatro questões de acordo com os conceitos norteadores de cada uma das abordagens teóricas da Educação Física (Esportivista, Psicomotricista, Desenvolvimentista e Crítico-superadora / emancipatória) e dispostas alternadamente para não provocar indução nas respostas no caso de identificação, pelo sujeito da relação da questão elaborada com a abordagem teórica de origem. Os dados coletados nestas questões foram tratados por uma análise para a identificação de ancoragem para a representação social identificado no estudo preliminar.

O grupo pesquisado foi composto por um conjunto de 105 professores de Educação Física com atuação pedagógica em escolas públicas e privadas no segmento de Ensino Fundamental I. A distribuição dos indivíduos entrevistados seguiu esta configuração: 50 professores atuantes em escolas públicas, 26 em escolas particulares e 29 em ambas.

A opção por este segmento se deu por este ser detentor de características importantes para a realização desta 
pesquisa como a faixa etária ${ }^{5}$ atendida pelas primeiras séries do Ensino Fundamental. Esta faixa etária compreende ao período de desenvolvimento motor humano no qual as aquisições psicomotoras já instaladas permitem a realização de atividades físicas que vão dos movimentos naturais rudimentares aos movimentos complexos (GALLAHUE, 2001). O que nos permite observar, no discurso referente às propostas oferecidas pelos professores no decorrer de suas aulas de Educação Física, elementos indicadores que estas atividades que possam ser organizadas a partir de conhecimentos e referenciais teóricos ancorados nos diversos modelos teóricos da Educação Física (DAOLIO, 2005).

Cabe ressaltar que o grupo de professores que responderam o questionário são professores atuantes em escolas possuidoras de características comuns como: a prática da Educação Física como disciplina obrigatória, oferta das aulas de Educação Física no mesmo turno que as demais disciplinas e aulas de Educação Física ministradas por professores de Educação Física formados em instituições de ensino superior.

\section{Resultados do estudo da ancoragem nas abordagens teóricas}

Na busca de "identificar a ancoragem do conteúdo das representações sociais identificadas em estudo preliminar e das práticas nas abordagens teóricas" assim como "discutir a influência dos modelos teóricos na prática dos professores de Educação Física". Com vistas a atender a identificação e análise prevista foram aplicadas questões relativas às estruturas teóricas das abordagens teóricas norteadoras da educação física escolar nos períodos distintos de sua existência.

A análise simples da frequência das respostas leva a supor que estes professores possivelmente organizam suas práticas ancoradas em princípios metodológicos que não estão estruturados em apenas uma das abordagens. Esta conclusão baseia-se no quadro de respostas descrito abaixo onde está expresso um percentual significativo de sujeitos que respondeu dizendo que "concordam muito" ou "concordam totalmente" com os princípios da Abordagem Psicomotora, Desenvolvimentista e um percentual também significativo de respostas concordantes com a presença dos princípios das abordagens críticas nas suas aulas.

Em relação à afirmação de que as atividades devam atender ao desenvolvimento afetivo, cognitivo e motor do aluno, que as atividades devem objetivar o desenvolvimento dos aspectos psicomotores e que as atividades devem valorizar a aprendizagem a partir dos movimentos espontâneos do aluno o percentual de professores que "concordam muito" e "concordam totalmente" foi expressivo. Estes princípios são princípios elaborados a partir da fundamentação teórica da Abordagem Psicomotora o que denota uma significativa concordância dos professores com estes princípios e, por conseguinte aplicação destes princípios

5 Aproximadamente entre 5 a 15 anos. A idade de conclusão do ensino fundamental I habitualmente é 10 ou 11 anos, no entanto, sabemos que quando o aluno sofre algum tipo de intercorrência em seu percurso escolar como repetência e outros a idade conclusão tende a ser superior. 
em suas aulas.

Também significativa, foi a configuração das respostas dos professores em relação aos princípios norteadores ditados pela Abordagem Desenvolvimentista. os professores, concordam que as atividades desenvolvidas nas aulas de Educação Física devem objetivar o desenvolvimento do comportamento motor, que o objetivo prin- cipal das atividades deve ser o de favorecer a progressão normal do crescimento físico na aprendizagem motora e acreditam que as atividades devem desenvolver a aprendizagem de habilidades motoras, onde o enfoque principal deve ser o desenvolvimento do comportamento motor.

Tabela 1: Quadro de distribuição dos percentuais de respostas "concordo muito" e "concordo totalmente".

\begin{tabular}{|c|c|c|}
\hline Abordagem & Questão & $\begin{array}{l}\text { Percentual de Respostas } \\
\text { "Concordo Muto" e } \\
\text { "Concordo Totalmente" }\end{array}$ \\
\hline \multirow{3}{*}{ Psicomotricista } & $\begin{array}{l}\text { Deve-se oferecer atividades que atenda ao desenvolvi- } \\
\text { mento cognitivo, afetivo e motor do aluno }\end{array}$ & $93 \%$ \\
\hline & $\begin{array}{l}\text { As atividades devem contribuir para o desenvolvimen- } \\
\text { to dos aspectos psicomotores: lateralidade, esquema } \\
\text { corpora limagem corporal, equilíbrio, coordenação } \\
\text { motora e noção espaço-temporal. }\end{array}$ & $86 \%$ \\
\hline & $\begin{array}{l}\text { O planejamento deve valorizar a aprendizagem a } \\
\text { partir dos movimentos espontâneos do aluno }\end{array}$ & $56 \%$ \\
\hline \multirow{3}{*}{ Desenvolvimentista } & $\begin{array}{l}\text { As atividades oferecidas devem respeitar a ordem } \\
\text { de complexidade dos movimentos: das habilidades } \\
\text { básicas as específicas e o desenvolvimento motor } \\
\text { específico de cada faixa etária }\end{array}$ & $85 \%$ \\
\hline & $\begin{array}{l}\text { O objetivo principal deve ser o de favorecer a pro- } \\
\text { gressão normal do crescimento físico na aprendiza- } \\
\text { gem motora. }\end{array}$ & $56 \%$ \\
\hline & $\begin{array}{l}\text { As atividades devem desenvolver a aprendizagem de } \\
\text { habilidades motoras, onde o enfoque principal deve } \\
\text { ser o desenvolvimento do comportamento motor. }\end{array}$ & $35 \%$ \\
\hline \multirow{3}{*}{ Críticas } & $\begin{array}{l}\text { As atividades propostas devem promover a amplia- } \\
\text { ção do raciocínio crítico e da autonomia dos alunos } \\
\text { valorizando a compreensão crítica do mundo, da } \\
\text { sociedade e de suas relações. }\end{array}$ & $80 \%$ \\
\hline & $\begin{array}{l}\text { As atividades devem enfatizar o conhecimento da } \\
\text { cultura corporal através do jogo, ginástica, dança, } \\
\text { esporte e capoeira. }\end{array}$ & $74 \%$ \\
\hline & $\begin{array}{l}\text { Os conteúdos devem ser formulados considerando sua } \\
\text { relevância social, sua contemporaneidade e adequação } \\
\text { às características sociais e cognitivas do aluno. }\end{array}$ & $72 \%$ \\
\hline \multirow{3}{*}{ Esportivista } & Deve-se priorizar o ensino das práticas esportivas & $10 \%$ \\
\hline & $\begin{array}{l}\text { Os professores devem preocupar-se com a correção } \\
\text { dos movimentos esportivos, buscando o melhor } \\
\text { rendimento. }\end{array}$ & $6 \%$ \\
\hline & $\begin{array}{l}\text { As atividades devem estar voltadas para o ensino das } \\
\text { técnicas dos esportes. }\end{array}$ & $3 \%$ \\
\hline
\end{tabular}


As abordagens Críticas apresentaram um percentual de respostas que demonstra uma significativa adesão aos princípios ditados por esta abordagem por parte dos professores que participaram desta pesquisa. Os professores concordam que as atividades propostas devem promover a ampliação do raciocínio crítico e da autonomia dos alunos valorizando a compreensão crítica do mundo, da sociedade e de suas relações, afirmam positivamente que as atividades devem enfatizar o conhecimento da cultura corporal através do jogo, ginástica, dança, esporte e capoeira e concordam conteúdos devem ser formulados considerando sua relevância social, sua contemporaneidade e adequação às características sociais e cognitivas do aluno. Este panorama em relação à expressão favorável dos professores de forma tão expressiva aos elementos que marcam a especificidade teórica das Abordagens Críticas pode ser explicada pelo fato de que existe uma reconhecida divulgação e orientação sobre os princípios teóricos desenvolvidos pelos autores das abordagens críticas, principalmente nos procedimentos de formação continuada oferecida aos professores de escola pública (CUNHA, 2009; NEIRA, 2009). No entanto estes "elementos novos" ainda não estão inseridos na prática destes indivíduos, pois os professores marcam a presença destes elementos apenas por meio de um discurso "pensado" o que não aparece nas questões onde os indivíduos são solicitados a expressar os elementos de sua prática de forma espontânea.

A abordagem esportivista recebeu um percentual mais expressivo de respostas "discordo totalmente", "discordo muito" e "discordo um pouco". Estes resultados indicam que os indivíduos organizam suas práticas em princípios metodológicos que não estão estruturados em apenas uma das abordagens. O que sugere que a prática da Educação Física Escolar apresenta uma aparente inconsistência teórica, indicando a ausência de uma formação sólida para a compreensão estruturada e definida dos princípios teóricos norteadores desta prática. Sugere ainda que os professores não têm claramente definidos os conhecimentos a respeito das abordagens (MALDONADO; HYPÓLITTO; LIMONGELLI, 2008; WATANABE; BIM, 2012) e, portanto a utilização de seus pressupostos metodológicos apresenta-se um tanto indefinida.

Ainda, de acordo com as respostas apresentadas, os indivíduos indicam que discordam de uma Educação Física Escolar que esteja a serviço da prática esportiva/ técnica, onde a prioridade seja o ensino das práticas e técnicas esportivas voltadas para a busca do melhor rendimento. Estas foram às questões com maior percentual de discordância por parte dos professores que responderam o questionário.

Aparentemente contraditório a este perfil de resposta apresentado pelos professores na verdade não o é, pois estas questões fazem parte de um conjunto de indagações presentes no questionário aplicado, que podemos dizer que são produtoras de um discurso que denominamos de "discurso cognitivado". Neste discurso os indivíduos se distanciam de uma prática que possa estar ancorada em uma abordagem esportivista. No entanto os resultados obtidos nas questões de livre evocação e, portanto por meio de um discurso que denominamos de "discurso espontâneo", estes mesmos professores trazem o "esporte" como a palavra mais 
evocada dentre todas e nas primeiras posições, dando a entender o quanto é forte a prática da Educação Física Escolar vinculada ao esporte, sugerindo uma prática onde o esporte é fundamentalmente utilizado. Outro argumento que também pode exposto é o fato de que os professores trazem o esporte como um instrumento mediador do desenvolvimento do aluno e não como um elemento promotor apenas de realizações motoras eminentemente técnicas

Aplicando os dados obtidos nestas questões no software para a realização de uma "análise de similitude" foi possível visualizar o seguinte gráfico apresentado na Figura 3.

Este gráfico nos permite trazer novas interpretações sobre os resultados obtidos anteriormente a respeito da influência das abordagens metodológicas da Educação Física na prática desta nas escolas. Podemos observar que os professores identificam a existência e a distinção entre as abordagens, mas é evidente que a abordagem que organiza o campo de ação da Educação Física é a Abordagem Desenvolvimentista, representada no gráfico acima pelos elementos que caracterizam seus pressupostos teóricos: crescimento físico, faixa etária e comportamento motor. Esta assume uma posição central nesta organização gráfica e, portanto na prática, interligando dois dos outros conjuntos de elementos mais significativos da Educação Física como expresso pelos professores, que são os elementos que se caracterizam a prática de acordo com os princípios da Abordagem Esportivista (prática esportivas, movimento esportivo e técnicas esportivas) e com da Abordagem Psicomotora (aspectos psicomotores, desenvolvimento integral e movimentos espontâneos).

As Abordagens Críticas também se fazem presentes, os professores as reconhecem enquanto componente norteador da prática da Educação Física e identificam-nas como referência a um ideal de prática, entendendo a sua importância, no entanto estes professores não a inserem em sua prática como pode ser percebido no gráfico acima. Os elementos constitutivos do conjunto das práticas segundo as Abordagens Críticas encontram-se em um gráfico dissociado das demais.

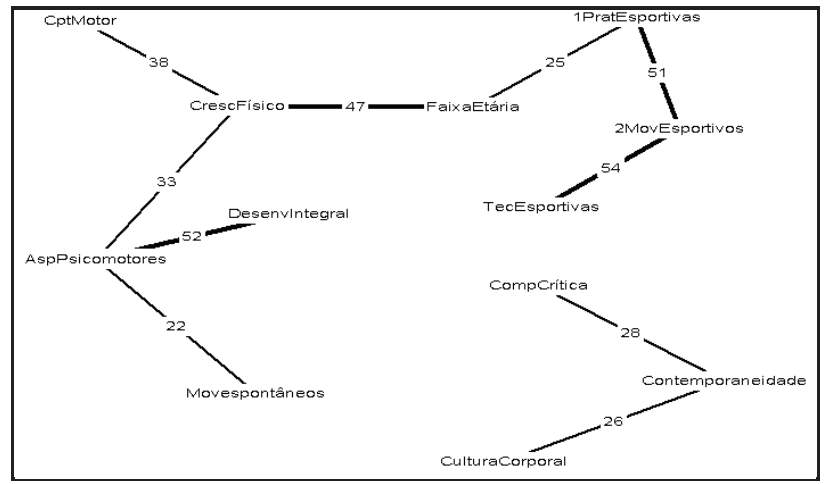

Figura 1: Análise das Abordagens Metodológicas da Educação Física Escolar de acordo com as respostas apresentadas pelos professores (árvore máxima)

Elaboração: programa de análise de similitude. 
O que podemos interpretar é que os professores apresentam um discurso normativo, institucional, ou seja, no discurso que denominamos "cognitivado" os indivíduos resgatam referenciais teóricos às tendências mais recentes e no discurso que denominamos "espontâneo" os professores referenciam sua prática de acordo com os princípios inscritos a partir das tendências que marcaram o início desta prática nas escolas brasileiras.

Este cenário também nos oferece indícios de que o ensino da Educação Física nas universidades demonstra uma assimilação das novas tendências metodológicas e que promove a expressão destes elementos no discurso dos professores. O que é descrito por estes sugere que as novas abordagens não imprimem o mesmo impacto na evolução do aluno em relação a um desenvolvimento que apresenta vínculo forte com o desenvolvimento de habilidades motoras. Há também uma inconsistência expressa no discurso destes professores, a respeito da definição e, portanto compreensão clara dos princípios metodológicos de cada abordagem. Os limites conceituais referentes às abordagens, por exemplo, Psicomotora e Desenvolvimentista não estão claramente definidos na concepção dos professores, estes fazem uma fusão entre os conceitos pertencentes a estas abordagens. As diversas Abordagens teóricas estão "coabitando" na prática destes professores, não há uma teoria dominante.

\section{DISCUSSÃO}

O estudo que envolve a compreensão de uma determinada Representação social é fundamental para que, uma vez identificando os seus elementos e compreendendo a dinâmica que estes elementos assumem, passamos a compreender a forma como os sujeitos se orientam em suas ações, orientam suas escolhas e no caso do estudo de uma prática social compreendemos a dinâmica de funcionamento desta prática. Deste modo somos capazes de também identificar os componentes que fragilizam esta prática e os componentes que a sustentam e ainda os componentes que possibilitam seus avanços e suas transformações.

Estudar as Representações Sociais da Educação Física Escolar nos direcionou a estudar os elementos que marcaram esta prática desde sua origem, pois quando os professores desta disciplina representam a Educação Física hoje, o fazem segundo referenciais estabelecidos nos valores, normas e opiniões construídas em torno desta prática desde o início de sua existência como prática constituída e ao longo de sua história.

A representação social encontrada da prática da Educação Física Escolar em estudo preliminar, descrita por seus professores está organizada de acordo com uma estrutura supostamente bem definida. O núcleo central está constituído pelos elementos "desenvolvimento" e "lúdico" e o sistema periférico estruturado pelo conjunto de elementos "esporte", "corpo", "jogos" e "movimento".

A análise dos dados do estudo atual, nos leva a concluir que a prática da Educação Física nas escolas é organizada a partir da Abordagem Desenvolvimentista, que assume uma posição de normatização desta prática, interligando os elementos que permeiam o campo conceitual das Abordagens Esportivista e Psicomotora. Os professores afirmam espontaneamente que o esporte é 
o principal instrumento aplicado em suas aulas, mas para que a prática esportiva se faça presente sem que esta seja caracterizada como uma prática vinculada aos modelos Tecnicista, Militarista ou mesmo o Esportivista, os princípios desenvolvimentistas são resgatados como justificativa a esta prática.

Os professores argumentam que o esporte está a serviço do desenvolvimento do aluno. Auxiliando na sustentação teórica desta prática, encontramos ainda conceitos advindos da Abordagem Psicomotora que trazem o sentido pedagógico para a prática da Educação Física, pois os seus pressupostos se baseiam na experimentação do corpo e no movimento como base para a aprendizagem acadêmica. Estes professores ainda reconhecem as Abordagens Críticas como um ideal de prática a ser concretizado, como elemento importante para a qualidade da prática da Educação Física, contudo estes conceitos não se encontram integrados aos conceitos referentes às outras abordagens. Este cenário pode ser explicado pelo fato de que há uma maciça disseminação dos pressupostos teóricos das Abordagens Críticas como a "Cultura corporal do movimento". No entanto, este discurso ainda não está presente na prática destes professores. Bracht (1999) e Darido (2003) relatam que a prática pedagógica na Educação Física ainda estava muito resistente a mudanças, e que apesar das mudanças sócio-políticas, a prática da Educação Física não foi influenciada por tal discurso. E de acordo com os resultados encontrados em nossa pesquisa, podemos vislumbrar possíveis mudanças em direção às Abordagens Críticas, mas isso ainda não constitui uma realidade estabelecida.

Os resultados obtidos parecem indicar ainda um possível processo de transformação nesta representação, o que por sua vez pode promover uma interferência na prática e, por sua vez, sofrer interferência de novas práticas. Esta transformação pode estar relacionada aos elementos que se fizeram presentes no sistema periférico, elementos relacionados aos princípios das abordagens mais recentes e os princípios definidos nos PCN como: "cultura", "cultura corporal do movimento" e "cooperação".

A transformação de uma Representação se desenvolve gradativamente a partir da absorção dos elementos novos à representação expressa, podendo acarretar em um processo reversível se o núcleo central for atingido ou irreversível quando implicar na modificação do núcleo central (CAMPOS, 2003). No caso da Representação identificada da prática da Educação Física Escolar, esta transformação pode tornar possível por meio da absorção dos elementos indicativos das Novas Abordagens, neste sentido as Abordagens Críticas e expressos na prática, ou seja, expressos na escolha das estratégias utilizadas pelos professores em suas aulas. O que sugere que a proposta pedagógica da Educação física está sustentada em objetivos que promovem o desenvolvimento, garantindo assim sua característica educativa e justificando uma prática que se utiliza de estratégias esportivas e lúdicas para a sua realização.

\section{REFERÊNCIAS}

ABRIC, Jean Claude. A abordagem estrutural das representações sociais. Tradução Pedro Humberto Campos. In: MOREIRA, A. S. P.; OLIVEIRA, D. C. (Org.). Estudos interdisciplinares de representações sociais. 2. ed. Goiânia: Ed. AB, 2000. 
. Práticas sociales y representaciones. México: Presses Universitaires de France, 2001.

ACCIOLY, Aluízio Ramos; MARINHO, Inezil. Pena. História e organização da Educação Física e dos Desportos. v. I, Rio de Janeiro: Baptista de Souza \& Cia Editores, 1956.

BARBIERI, Aline Fabiane; PORELLI, Ana Beatriz Gasquez; MELLO, Rosângela Aparecida Abordagens, concepções e perspectivas de Educação Física quanto à metodologia de ensino nos trabalhos publicados na Revista Brasileira de Ciência do Esporte em 2009. Motrivivência, a. XX, n. 31, p. 223-240, dez. 2010.

BETTI, Mauro. Educação Física como prática científica e prática pedagógica: reflexões à luz da filosofia da ciência. Revista Brasileira de Educação Física e Esporte. v. 19, n. 3, São Paulo, p. 183-197, set. 2005.

BRACHT, Valter. A constituição das teorias pedagógicas de educação física. Cad. CEDES. vol. 19. n. 48. Campinas. Aug. 1999.

BRACHT, Valter; GONZÁLEZ, Fernando Jaime. Educação Física Escolar. In: GONZÁLEZ, F. J.; FENSTERSEIFER, P. E. (Org.). Dicionário crítico de Educação Física. ljuí: Unijuí/RS, 2005, p. 150-156. BRACHT, Valter. As culturas da Educação Física. Revista Brasileira Ciências do Esporte. Campinas/SP, v.32, n.1, p.93-107. set. 2010.

BRASIL. Presidência da República. Decreto n 69.450 de $1^{\circ}$ de novembro de 1971. In: SÃO PAULO (Estado). Secretaria Estadual de Educação. Coordenadoria de Dez anos de parâmetros curriculares nacionais: a prática. 125, Porto Alegre, v. 15 , n. 04 , p. 107-126, outubro/ dezembro de 2009.

Secretaria de Educação Fundamental. PCN: Educação Física. DP\&A. RJ, 2000.

CAMPOS, Pedro Humberto Faria. A abordagem estrutural e o estudo das relações entre as práticas e representações sociais. In: CAMPOS, P. H. F.; LOUREIRO, M. C. da S. (Org.). Representações sociais e práticas educativas. Goiânia: Ed. da UCG, 2003. CAMPOS, Luiz Antônio Silva. Didática da Educação Física. Várzea Paulista, SP: Fontoura, 2011.

CARVALHO, Fernando Luiz Seixas Faria. O Papel da Educação Física Escolar representado por professores e professoras de outras disciplinas. 2006. 137f. Dissertação (Mestrado em Educação) - Universidade Federal de Juiz de Fora, Juiz de Fora, 2006.

CASTELLANI FILHO, Lino. Educação Física no Brasil: a história que não se conta. Campinas/SP: Papirus, 1988.

CASTELLANI FILHO, Lino. et al.Metodologia do ensino da educação física. 2. ed. rev. São Paulo: Cortez, 2009.

CUNHA, Virgínia Maria Próspero. Repensando a avaliação: As representações sociais compartilhadas pelos professores de educação física. 2009. 168f. Tese (Doutorado em educação) - Pontifícia Universidade Católica, São Paulo, 2009.

DARIDO, Suraya Cristina; RANGEL, Irene Conceição Andrade. Educação física na escola: implicações para a prática pedagógica. Rio de Janeiro: Guanabara Koogan, 2008. 
DARIDO, Suraya Cristina. Educação física na escola: questões e reflexões. Rio de Janeiro: Guanabara Koogan, 2003.

DAOLIO, Jocimar. Futebol, cultura e Sociedade. Campinas: Autores Associados, 2005.

. Educação Física escolar: em busca da pluralidade. São Paulo: Escola de Educação Física e Esporte da Universidade de São Paulo. Revista Paulista de Educação Física. suplemento. 2, p. 40-42, 1996.

DECHAMPS, Jean-Claude; MOLINER, Pascal. A identidade em psicologia social dos processos identitários às representações sociais. Petrópolis, RJ: Vozes, 2009.

FENSTERSEIFER, Paulo Evaldo. Epistemologia e Prática pedagógica. Revista Brasileira Ciência do Esporte. Campinas, SP, v. 30, p. 203-214. maio 2009.

FREIRE, João Batista da Silva.Educação de corpo inteiro: teoria e prática da educação física. Campinas/SP: Scipione, 1989.

GALLAHUE, David e OZMUN, John. Compreendendo o desenvolvimento motor: bebês, crianças, adolescentes e adultos. Guarulhos: Phorte Editora, 2001.

HILDEBRANDT, Reiner. Concepções Abertas no Ensino da Educação Física. Rio de Janeiro: Ao Livro Técnico, 1986. LAVOURA, Tiago Nicola; BOTURA, Henrique Moura Leite; DARIDO, Suraya Cristina. Educação Física Escolar: conhecimentos necessários à prática pedagógica. Revista de Educação Física da UEM, Maringá/PR, v. 17, n. 2, p. 203-209, 2006.
LE BOULCH, Jean. O Desenvolvimento psicomotor: do nascimento até os 6 anos. 4. ed. Porto Alegre: Artes Médicas, 1986.

MALDONADO, Daniel Teixeira; HYPOLITO, Dinéia; LIMONGELLI, Ana Martha de Almeida Conhecimento dos professores de Educação Física Escolar. Revista Mackenzie de Educação Física e Esporte, São Paulo, v. 7, n. 3, p. 13-19, 2008.

MEDINA, J. P. S. A educação física cuida do corpo e... "mente". Campinas/SP: Papirus, 1983.

MOSCOVICI,Serge. Representações sociais: investigações em psicologia social. 7. ed. Petrópolis/RJ: Vozes, 2010. NEIRA, Marcos Garcia. Educação Física desenvolvendo competências. 3. ed. São Paulo: Phorte, 2009.

PEREIRA, Giane Moreira Santos. Representações sociais de educação física: o resgate e o remédio do corpo e da mente. 2007. 115f. Dissertação (Mestrado em Educação) - Universidade Estácio de Sá, Rio de Janeiro, 2007.

RETONDAR, Moebus José. As representações sociais do ato pedagógico dos professores de educação física que atuam no ensino fundamental no Município do Rio de Janeiro. Motrivivência, a. XXI, n. 32/33, p. 211-229, jun./dez. 2009.

REZER, Ricardo. Relações entre conhecimento e prática pedagógica no campo da Educação Física: pontos de vista. Motrivivência, a. XIX, v. 28, p. 38-62. abr. 2009.

SÁ, Ivo Ribeiro. Representações Sociais: a Educação Física Escolar em pauta. In: FONTOURA P. (Org.). Coleção 
V. $26, n^{\circ} 43$, dezembro/2014

Pesquisa em Educação Física. v. 4, p. 257-263, Jundiaí, SP: Fontoura Editora, 2006.

SÉRGIO, Manuel. Para uma epistemologia da motricidade humana: prolegômenos a uma ciência do homem. Lisboa: Compendium, 1987. (Doutorado em Educação Física) - Universidade Gama Filho, Rio de Janeiro, 2007.

TANI, Go. et al. Educação física escolar: fundamentos de uma abordagem desenvolvimentista. São Paulo: Ed. da USP, 1988.

WACHELKE, João FernandoRech; CAMARGO, Brigido Vizeu.
Representações sociais, representações individuais e comportamento. Revista Interamericana de Psicologia. v. 41, n. 3, p. 379-390, 2007.

WATANABE, Márcia Massae; BIM, Ricardo Henrique. 2012. Propostas pedagógicas para o ensino da Educação Física na escola. Muita teoria e pouca prática (ainda)? EFDeportes.com, Revista Digital. Buenos Aires, a. 16, n. 165, Fev., 2012. Disponível em: < http:// www.efdeportes.com. Acesso em: 23 de outubro de $2011>$.

\title{
SOCIAL REPRESENTATION OF THE ANCHORAGE SCHOOL PHYSICAL EDUCATION IN THEORETICAL APPROACHES OF PHYSICAL EDUCATION
}

\begin{abstract}
This study aimed to investigate the practice of physical education in schools from the perspective of social representations the or in order to identify anchoring of social representations in Theoretical Models of this discipline. Based on previous study where the social representation is based on the factors identified: playful and DEVELOPMENT central elements, the results obtained in this study indicate that the Social Representation identified is anchored in the approaches: Developmental and Psychomotor. We suggest that the practice of physical education at the service of DEVELOPMENT and this development is promoted primarily through strategies SPORT and LEISURE.
\end{abstract}

Keywords: Social Representations; Physical Education 


\section{ANCLAJE DE LA REPRESENTACIÓN SOCIAL DE LA EDUCACIÓN FÍSICA ESCOLAR EN LOS ABORDAJES TEÓRICOS DE LA EDUCACIÓN FÍSICA}

\section{RESUMEN}

Este estudio propuso investigar la práctica de la Educación Física en las escuelas bajo la óptica de la Teoría de las Representaciones Sociales en la búsqueda de la identificación del anclaje de las representaciones sociales en los Modelos Teóricos de esta disciplina. Basado en estudio anterior donde la representación social identificada está fundamentada en los elementos: LÚDICO y DESARROLLO como elementos céntricos, los resultados obtenidos en el actual estudio indican que la Representación Social identificada está anclada en los abordajes: del Desarrollo y lo Psicomotor. Podemos sugerir aunque la práctica de la Educación Física escolar está a servicio del DESARROLLO y este desarrollo es promovido principalmente por medio de estrategias LÚDICAS y DEPORTIVAS.

Palabras clave: Representaciones Sociales; Educación Física Escolar

Recebido em: abril/2014

Aprovado em: julho/2014 